\title{
THE FUNDAMENTALS OF DETERMINING THE RENTAL CHARGE FOR THE STATE-OWNED REAL ESTATE IN THE RUSSIAN FEDERATION ${ }^{1}$
}

\author{
Ekaterina M. Vavilova \\ Financial University under the Government of the Russian Federation, Moscow, Russian Federation
}

\begin{abstract}
Introduction: the paper discusses the study of the basic principles and methods of determining rental rates for the use of land owned by the state and municipal authorities. Despite the increasing trend of the privatization of state-owned land, its significant proportion is still under the state ownership. In this regard, a significant share of court proceedings in the Arbitration courts falls precisely on those disputes that relate to the determination of the procedure for establishing the rent of state-owned real estate in Russia. In this regard, the author set the goal to study the problem of establishing the amount of the rent for the land held by tenants for housing after bringing into force Resolution of the Government of the Russian Government No. 582 of July 16, 2009 "On the basic principles of determining the rent for leases of land plots in the state or municipal ownership, and on the Rules for determining the amount of rent and the order of the conditions and terms of payment of rent for land in the ownership of the Russian Federation" (hereinafter - "Resolution No. 582"). Methods: the methodological framework for the study is a set of methods of scientific knowledge, among which the main one is the comparative law method, as well as the methods of systematization and analysis. Results: the author's position grounded in the work is based on the analysis of the legislation and the opinions of the scientists expressed in the competent scientific community on the issue of establishing the basic rates for renting the state real estate. Conclusions: as a result of the study, the main principles of determining the rates for renting the state-owned real estate, as well as the procedure for determining them, were analyzed. It was established that the amount of rent for land plots that were provided to tenants for housing construction after the entry into force of Resolution No. 582 should not exceed $2 \%$ of the cadastral value of such real estate.
\end{abstract}

Keywords: rent, state real estate, order establishing, land lease, land legal relations.

Citation. Vavilova E.M. The Fundamentals of Determining the Rental Charge for the State-Owned Real Estate in the Russian Federation. Legal Concept = Pravovaya paradigma, 2021, vol. 20, no. 1, pp. 94-98. (in Russian). DOI: https://doi.org/10.15688/lc.jvolsu.2021.1.14

УДК 349.4

Дата поступления статьи: 28.12.2020

ББК 67.407 .1

Дата принятия статьи: 28.01.2021

\section{ОСНОВЫ ОПРЕДЕЛЕНИЯ СТОИМОСТИ АРЕНДНОЙ ПЛАТЫ ГОСУДАРСТВЕННОЙ НЕДВИЖИМОСТИ РОССИЙСКОЙ ФЕДЕРАЦИИ ${ }^{1}$}

\author{
Екатерина Михайловна Вавилова \\ Финансовый университет при Правительстве Российской Федерации (Финуниверситет), \\ г. Москва, Российская Федерация
}

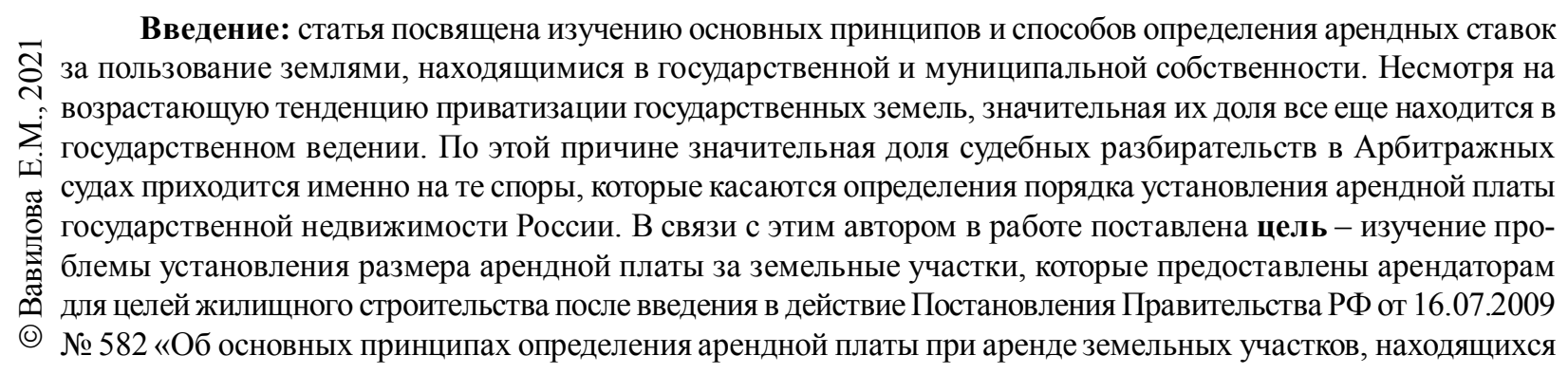


в государственной или муниципальной собственности, и о Правилах определения размера арендной платы, а также порядка, условий и сроков внесения арендной платы за земли, находящиеся в собственности Российской Федерации» (далее - «Постановление № 582»). Методы: методологическую основу настоящего исследования составляет совокупность методов научного познания, среди которых основное место занимает сравнительно-правовой метод, а также методы системности и анализа. Результаты: обоснованная в работе авторская позиция построена на анализе законодательства и мнений ученых, выраженных в компетентной научной среде по вопросу об установлении базовых ставок по аренде государственной недвижимости. Выводы: в результате исследования были проанализированы основные принципы определения ставок по аренде государственной недвижимости, а также порядок их определения. Было установлено, что размер арендной платы за земельные участки, которые предоставлены арендаторам для целей жилищного строительства после введения в действие Постановления № 582, не должен превышать $2 \%$ от кадастровой стоимости такой недвижимости.

Ключевые слова: арендная плата, государственная недвижимость, определение порядка, аренда земельных участков, земельные правоотношения.

Цитирование. Вавилова Е. М. Основы определения стоимости арендной платы государственной недвижимости Российской Федерации // Legal Concept = Правовая парадигма. - 2021. - Т. 20, № 1. - C. 94-98. - DOI: https://doi.org/10.15688/lc.jvolsu.2021.1.14

\section{Введение}

Вопрос определения стоимости арендной платы государственной недвижимости в России является актуальным для современной системы земельных правоотношений, поскольку кроет под собой ряд неопределенностей и споров, связанных, в том числе, с несоответствием установленных ставок основным принципам определения арендной ставки за публичные земли на территории России, а также предельным ставкам за определенные категории земель [8, с. 184].

Земельным кодексом Российской Федерации [3, ст. 8] предусмотрено, что земельные участки могут находится в государственной, муниципальной и частной собственности. Несмотря на возрастающую тенденцию приватизации государственных земель, значительная их доля все еще находится в государственном ведении. Стоит отметить, что на международном уровне за последние 25-30 лет отмечается усиление государственного (общественного) воздействия на земельный строй [6]. С возрастанием ограниченности земельных ресурсов, общественные интересы выступают на стыке с частнособственническим укладом, что служит основой многочисленным судебным спорам. Как справедливо отмечает судья Арбитражного суда СевероЗападного округа - И.Л. Грачева, арбитражные споры по аренде земель в частной собственности, а также вопросы, связанные с платежами, составляют крайне малую долю при сравнении со спорами, связанными с арендой государственных и муниципальных земель [1, с. 63-84].

Таким образом, справедливо сделать вывод о наличии множества проблем в рассматриваемой области, а также о разнополюсном их толковании как со стороны землепользователей, так и со стороны судов различных инстанций.

\section{Порядок определения арендной платы при аренде земельных участков, находящихся в государственной или муниципальной собственности}

Соблюдая принцип платности землепользования, законодательство установило, что порядок определения размер арендной платы, а также порядок, условия и сроки внесения арендной платы за земли, находящиеся в государственной собственности, устанавливается Правительством Российской Федерации, органами государственной власти субъектов Российской Федерации, органами местного самоуправления [3, ст. 65].

В связи с этим, Правительством Российской Федерации было принято Постановление № 582 [5]. В последнем выделяется семь принципов, приведенных в таблице.

В дополнение к этому названное постановление устанавливает следующие способы, в соответствии с которыми определяется раз- 


\section{ВОПРОСЫ ЧАСТНОПРАВОВОГО РЕГУЛИРОВАНИЯ}

мер арендной платы при аренде государственных земельных участков (рис. 1).

Приведенные выше принципы и способы определения арендной платы зачастую не соблюдаются арендодателями, что провоцирует появление судебных споров, инициированных землепользователями (арендаторами) [4].

Существенной проблемой в контексте рассматриваемой темы является установление размера арендной платы за земельные участки, которые предоставлены арендаторам для целей жилищного строительства после введения в действие Постановления № 582 .

В связи с этим следует вновь обратиться к положениям Постановления № 582, закрепляющим основополагающие принципы ус- тановления арендных платежей. В частности, принцип экономической обоснованности предполагает, что для земель одного населенного пункта, разрешенного пользования и назначения, а также используемых в рамках одного вида деятельности не могут быть введены арендные платежи свыше тех, что установлены для федерльных земель.

Законодательством установлено, что арендная ставка при предоставлении земельного участка в аренду для строительства при надлежащем согласовании места размещения объекта, не может быть выше $2 \%$ от кадастровой стоимости земельного участка [5].

Действующим российским законодательством жилищное строительство относит-

\section{Принципы, установленные Постановлением № 582}

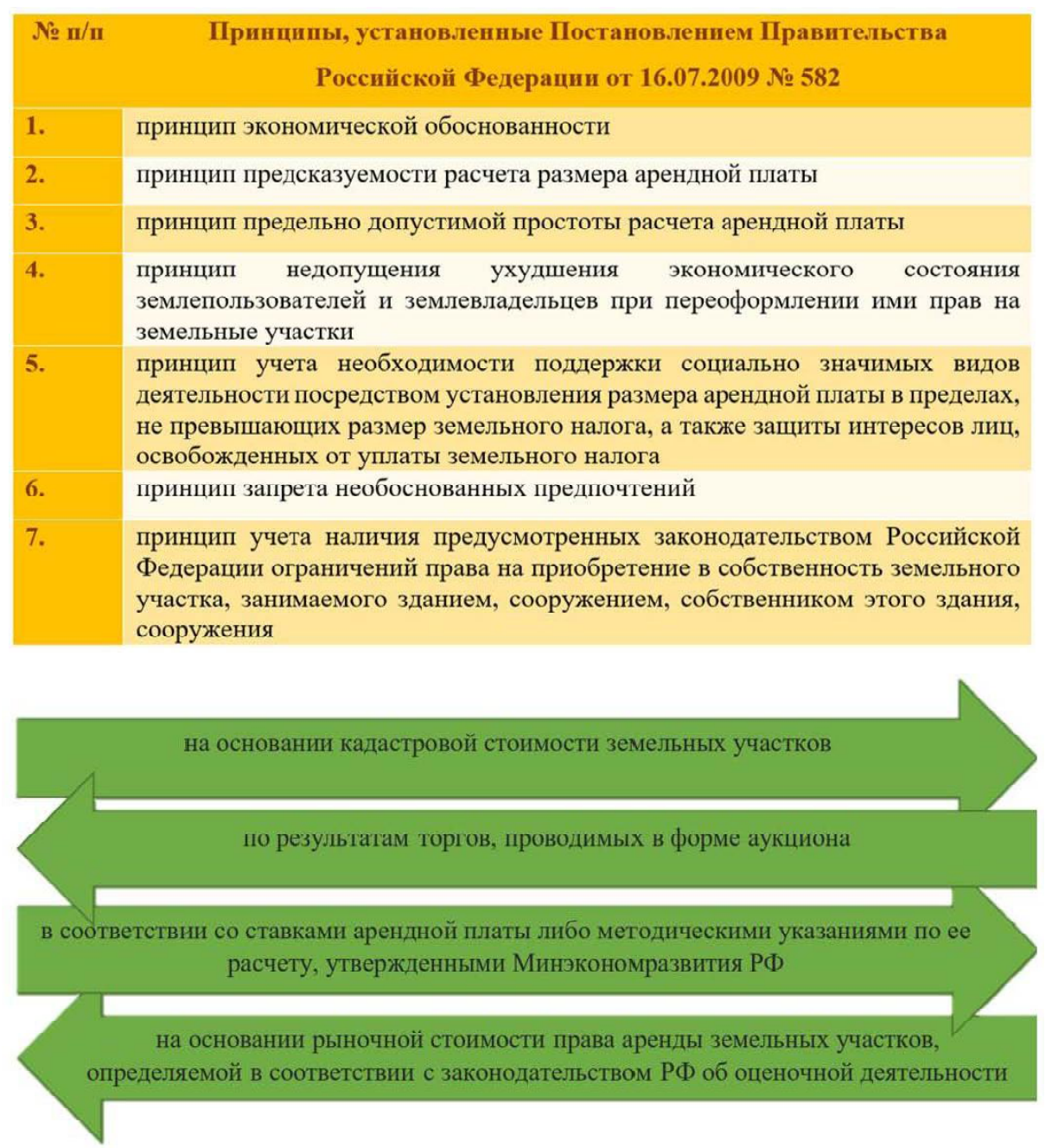

Рис. 1. Способы определения размера арендной платы при аренде государственных земельных участков 
ся к видам деятельности социально значимого характера. Таким образом, следуя названному выше пп. «д» п. 3 Правил определения арендной платы, размер арендной ставки не может превышать $2 \%$.

Вместе с тем в судебной практике встречались случаи, когда размер арендных платежей превышал установленную норму, доходя до 5 \% (например, дело № А66-3960/2013 [2]).

Между тем в рамках названного дела суды справедливо установили, что взимание арендной ставки, превышающей $2 \%$, не соответствует положениям действующего законодательства и не может быть взыскано с арендаторов.

\section{Заключение}

Подводя итог, можно сделать вывод о том, что платежи за предоставленные в аренду земельные участки в порядке п. 15 ст. 3 Закона № 137-Ф3 «О введении в действие Земельного кодекса Российской Федерации» [7] должны рассчитываться исходя из требований пп. «д〉 П. 3 названных Правил, если земли были введены в эксплуатацию в установленный законом срок. Если же введение в эксплуатацию произошло с нарушением срока, расчет должен происходить с учетом повышающих коэффициентов [1, с. 63-84].

В статье были проанализированы основные принципы определения ставок по аренде государственной недвижимости, а также порядок их определения. Кроме того, в процессе изучения судебной практики было установлено, что размер арендной платы за земельные участки, которые предоставлены арендаторам для целей жилищного строительства после введения в действие Постановления № 582, не должен быть свыше $2 \%$ от кадастровой стоимости такой недвижимости.

\section{ПРИМЕЧАНИЕ}

${ }^{1}$ Статья подготовлена по результатам исследований, выполненных за счет бюджетных средств по государственному заданию Финуниверситету.

The article was prepared based on the results of the publicly funded research by order of Financial University under the Government of the Russian Federation.

\section{СПИСОК ЛИТЕРАТУРЫ}

1. Грачева, И. Л. Отдельные вопросы судебной практики по спорам о взыскании платы за пользование земельными участками / И. Л. Грачева // Арбитражные споры. - 2015. - № 2. - С. 63-84.

2. Дело № А66-3960/2013.- Электрон. текстовые дан. - Режим доступа: https://kad.arbitr.ru/Card/ 9a31adb0-a7b5-410d-ac5d-835191e98ce6 (дата обращения: 24.12.2020). - Загл. с экрана.

3. «Земельный кодекс Российской Федерации» от 25.10.2001 № 136-Ф3 // Собрание законодательства РФ. - 2001. - 29 окт. (№ 44). - Ст. 4147.

4. Кацайлиди, А. В. Споры по аренде земельных участков / А. В. Кацайлиди. - Электрон. текстовые дан. - Режим доступа: https://katsaylidi.ru/ article/sporyi-po-arende-zemelnyih-uchastkov (дата обращения: 24.12.2020). - Загл. с экрана.

5. Постановление Правительства РФ от 16.07.2009 № 582 «Об основных принципах определения арендной платы при аренде земельных участков, находящихся в государственной или муниципальной собственности, и о Правилах определения размера арендной платы, а также порядка, условий и сроков внесения арендной платы за земли, находящиеся в собственности Российской Федерации» // Собрание законодательства РФ. - 2009. - 27 июля (№ 30). - Ст. 3821 .

6. Реформирования земельных отношений в России. - Электрон. текстовые дан. - Режим доступа: https://studfile.net/preview/2548710/page:3 (дата обращения: 24.12.2020). - Загл. с экрана.

7. Федеральный закон от 25.10.2001 № 137-Ф3 «О введении в действие Земельного кодекса Российской Федерации» // Собрание законодательства РФ. - 2001. - 29 окт. (№ 44). - Ст. 4148.

8. Чернышова, О. Н. Основные аспекты проведения оценки права на заключение договоров аренды объектов недвижимости, находящихся в государственной или муниципальной собственности / О. Н. Чернышова, В. Ю. Сутягин, Р. Ю. Черкашнев // Вестник Северо-Кавказского федерального университета. 2019. - № 6 (75). - С. 183-193.

\section{REFERENCES}

1. Gracheva I.L. Nekotoryye voprosy sudebnoy praktiki po sporam o vzyskanii platy za polzovaniye zemelnymi uchastkami [Some Questions of Judicial Practice on Disputes About the Collection of Fees for the Use of Land Plots]. Arbitrazhnyye spory [Arbitration Disputes], 2015, no. 2, pp. 63-84.

2. Delo no. A66-3960/2013 [Case no. A66-3960/ 2013]. URL: https://kad.arbitr.ru/Card/9a31adb0-a7b5410d-ac5d-835191e98ce6 (accessed 24 December 2020). 
3. «Zemelnyy kodeks Rossiyskoy Federatsii» ot 25.10.2001 № 136-FZ ["Land Code of the Russian Federation" Dated 25 October 2001 No. 136-FL]. Sobranie zakonodatelstva Rossiyskoy Federatsii [Collection of Legislation of the Russian Federation], 2001, Oct. 29 (no. 44), art. 4147.

4. Katsailidi A.V. Spory ob arende zemelnykh uchastkov [Disputes over the Lease of Land Plots]. URL: https://katsaylidi.ru/article/sporyi-po-arendezemelnyih-uchastkov (accessed 24 December 2020).

5. Postanovleniye Pravitelstva Rossiyskoy Federatsii ot 16.07.2009 № 582 «Ob osnovnykh printsipakh opredeleniyaarendnoy platy pri arende zemelnykh uchastkov, nakhodyashchikhsya $\mathrm{v}$ gosudarstvennoy ili munitsipalnoy sobstvennosti, i o pravilakh opredeleniya razmeraarendnoy platy, a takzhe poryadke, usloviyakh i srokakh vneseniyaarendnoy platy za zemelnyye uchastki, nakhodyashchiyesya v sobstvennosti Rossiyskoy Federatsii» [Resolution of the Government of the Russian Federation of 16.07.2009 No. 582 "On the Basic Principles of Determining Rent When Renting Land Plots that are in State or Municipal Ownership, and on the Rules for Determining the Amount of Rent, as Well as the Procedure, Conditions and Terms of Making
Rent for Land Owned by the Russian Federation"]. Sobranie zakonodatelstva Rossiyskoy Federatsii [Collection of Legislation of the Russian Federation], 2009, July 27 (no. 30), art. 3821.

6. Reforma zemelnykh otnosheniy v Rossii [Land Relations Reform in Russia]. URL: https://studfile.net/ preview/2548710/page:3 (accessed 24 December 2020).

7. Federalnyi zakon ot 25.10.2001 № 137-FZ «O vvedenii v deystviye Zemelnogo kodeksa Rossiyskoy Federatsii» [Federal Law Dated 25 October 2001 No. 137-FL "On the Introduction of the Land Code of the Russian Federation"]. Sobranie zakonodatelstva Rossiyskoy Federatsii [Collection of Legislation of the Russian Federation], 2001, Oct. 29 (no. 44), art. 4148.

8. Chernyshova O.N., Sutyagin V.Yu., Cherkashnev R.Yu. Osnovnyye aspekty otsenki prava na zaklyucheniye dogovorov arendy obyektov nedvizhimosti, nakhodyashchikhsya v gosudarstvennoy ili munitsipalnoy sobstvennosti [The Main Aspects of the Assessment of the Right to Conclude Lease Agreements for Real Estate Objects that are in State or Municipal Ownership].Vestnik Severo-Kavkazskogo federalnogo universiteta [Bulletin of the North Caucasus Federal University], 2019, no. 6(75), pp. 183-193.

\section{Information About the Author}

Ekaterina M. Vavilova, Postgraduate Student, Faculty of Law, Department of Legal Regulation of Economic Activity, Financial University under the Government of the Russian Federation, Prosp. Leningradskiy, 49, 125167 Moscow, Russian Federation, academy@fa.ru, Katyashh@bk.ru, https://orcid.org/0000-0003-2838-5208

\section{Информация об авторе}

Екатерина Михайловна Вавилова, аспирант Юридического факультета, Департамент правового регулирования экономической деятельности, Финансовый университет при Правительстве Российской Федерации (Финуниверситет), просп. Ленинградский, 49, 125167 г. Москва, Российская Федерация, academy@fa.ru, Katyashh@bk.ru, https://orcid.org/0000-0003-2838-5208 